\title{
The Events' Industry In Qatar And Social Behaviour Change Promotion Efforts: Green And Active Living Messaging And Anticipations In Light Of The 2022 FIFA
}

\author{
$\underline{10.5339 / \mathrm{gfarc} .2014 . \mathrm{SSPP} 1124}$
}

Eleni Theodorak; Sohair Abul Haija; Jane Ali-knight; Dan Musinguzi; Maktoba Omar; Jesus Canduela; Stephanie Bourne

Corresponding AUTHOR:

E.Theodoraki@napier.ac.uk

Edinburgh Napier University, Edinburgh, United Kingdom

\section{Abstract}

Qatar's growth, in terms of economic and political influence, is documented extensively in the literature and part of the country's long-term strategy for future development involves a growing events' industry. Having previously hosted the Asian Games and been awarded the rights to hold the 2022 FIFA World Cup the country is also host to numerous artistic, music, political and business events.

In addition to host city destination promotion, and tourism development related impacts, leveraging of events' hosting for social behaviour change purposes has recently been utilised by the events' industry/ host governments and is reported in the academic literature.

The study presented here is stage one of a three partite project funded by the National Priorities Research Programme. It sought to identify the organisations that make up the events' industry in Qatar with the view to evaluate event managers': perceptions of the context of 'green' and 'active' living promotion in the country, internally and externally available resources to this effect, extent of pro behaviour change message promotion during events, main influencers for pro 'green' and active' living issues and perceived effectiveness of such efforts. Stage one of the study also sought to capture managers' perceived anticipations of changes in light of preparations for hosting the 2022 FIFA World Cup and the extent to which managers envisage utilising the momentum from such a mega event to further promote 'green' and 'active' living messages to staff, event attendees and other external stakeholders.

Following a literature review of event leveraging and the context of event hosting and promotion of 'green' and 'active' living in Qatar the study employed a questionnaire survey to capture the event's industry demography. In the absence of a representative body/federation, of which events' organisations are members, and given that many event management tasks are performed in-house by departments of bigger organisations, the researchers developed a database of event management contacts $(\mathrm{N}=135)$. A11 of these were asked to fill in an Arabic or English language version of a 16 point questionnaire, and twenty-eight managers responded.

The findings support the literature as regards the context of Qatar in terms of 'green' and 'active' living promotion efforts and also show evidence of expectations of mega event leveraging for behaviour change. Notwithstanding the limitations of the small sample size and descriptive nature of this first stage of the research the paper makes a methodological contribution with the development of the research instrument for assessing organisational behaviour change messaging in the events' industry. It also offers a snapshot of managers' views of Qatar's context as regards 'green' and 'active' living promotion related capabilities, key influencers and anticipated developments in light of the preparations for hosting the 2022 FIFA World Cup-Qatar. 